\title{
A vivência da metodologia da problematização na formação docente
}

\author{
Ana Maria Di Grado Hessel* \\ Marina Moretzsohn Portella da Costa** \\ Maria Otilia José Montessanti Mathias ${ }^{* * *}$
}

\section{Resumo}

O texto relata uma pesquisa referente ao uso da metodologia da problematização com o Arco de Maguerez, como método de ensino, desenvolvido em duas disciplinas do curso de Pedagogia da PUC-SP. O objetivo da pesquisa foi refletir sobre o ensino e aprendizagem, junto aos alunos do curso, os quais vivenciaram uma experiência didática. É uma pesquisa qualitativa de caráter exploratório. A experiência foi avaliada pelos alunos por meio de fichas avaliativas, postadas no ambiente Moodle. Esse ambiente também serviu como suporte para o desenvolvimento e acompanhamento das diferentes etapas da metodologia de problematização. As respostas oriundas das avaliações discentes subsidiaram a análise e interpretação dos dados que revelaram as aprendizagens concretizadas, bem como as contribuições para a formação docente crítica e reflexiva.

Palavras-chave: metodologia da problematização; método de ensino; formação docente.

*** Doutora e mestre em Educação e Currículo pela PUC-SP, professora da Faculdade de Educação, credenciada no Programa de Estudos Pós-Graduados em Tecnologias da Inteligência e Design Digital da PUC-SP. digrado@uol. com.br

** Graduada em Engenharia Têxtil e especialista em Controladoria e Auditoria pela Fundação Educacional Inaciana Padre Sabóia de Medeiros, graduanda em Pedagogia da PUC-SP. marinamoretzsohn@hotmail.com

*** Doutora em Psicologia da Educação pela PUC-SP, mestre em Educação e Currículo pela PUC-SP, professora da Faculdade de Educação da PUC-SP, professora dos cursos de Pedagogia e História da PUC-SP, chefe do Departamento de Educação: formação docente, gestão e tecnologia da PUC-SP. momathias@dialdata.com.br 


\title{
The experience of the methodology of problema- tization in teacher development
}

\begin{abstract}
The text reports a research concerning the use of the methodology of problematization with the Arch of Maguerez, as a teaching method, developed in two disciplines of the Pedagogy course of the Pontifical Catholic University in São Paulo. The objective of the research was to reflect on teaching and learning, along with the students, who experienced a didactic experience. It is a qualitative exploratory research. The experience was evaluated by the students through assessment sheets, posted in the Moodle environment. This environment also served as a support for the development and monitoring of the different stages of the methodology of problematization. The answers from the student evaluations were used for the analysis and interpretation of the data that revealed the effective learning, as well as the contributions to critical and reflective teacher development.
\end{abstract}

Keywords: problem methodology; teaching method; teacher training.

\section{Vivencia de la metodologia de la problemática en la formación docente}

\section{Resumen}

El texto relata una búsqueda referente al uso de la metodología de la problemática con el Arco de Manguerez, como método de enseñanza, desarrollado en dos disciplinas del curso de Pedagogía de PUC-SP. El objetivo de la búsqueda fue reflexionar sobre la enseñanza y aprendizaje, junto a los alumnos del curso, los cuáles participaron en una experiencia didáctica. Es una investigación cualitativa de carácter exploratorio. La experiencia fue evaluada por los alumnos a través de fichas de evaluación, publicadas en la plataforma Moodle. Esa plataforma sirvió como soporte para el desarrollo y acompañamiento de las diferentes etapas de la metodología de la problemática. Las respuestas obtenidas en las evaluaciones de los estudiantes apoyaron el análisis e interpretación de los datos que rebelaron los aprendizajes concretos, así como las contribuciones para la formación docente críica y reflexiva.

Palabras-clave: metodología de la problemática; método de enseñanza; formación docente. 


\section{Introdução}

Este artigo relata uma pesquisa sobre o uso da metodologia da problematização com o Arco de Maguerez (BERBEL, 2012), como um método de ensino. Foi desenvolvida em duas unidades temáticas componentes da matriz curricular do curso de Pedagogia da PUC-SP, denominadas Metodologias Específicas: natureza, ciências, meio ambiente, saúde ( $6^{\circ}$ período) e Escola: diferentes espaços e serviços de apoio pedagógico ( $8^{\circ}$ período).

A investigação teve como principal objetivo avaliar, junto aos alunos participantes, os resultados da aplicação da metodologia como método de ensino nas duas unidades temáticas do curso de Pedagogia. O objetivo específico foi identificar as contribuições promovidas na aprendizagem e no ensino pela metodologia da problematização com o Arco de Maguerez.

A pesquisa caracterizou-se como qualitativa e de caráter exploratório. Foi desenvolvida em três etapas: revisão bibliográfica, com o objetivo de promover maior aproximação com o problema investigado; análise e tratamento das informações fornecidas pelas fichas de autoavaliação e ficha de avaliação da unidade didática; e elaboração das considerações finais. As informações sobre os resultados da experiência didática foram coletadas por meio de um instrumental avaliativo on-line. Ao final do semestre letivo, os alunos envolvidos avaliaram o desenvolvimento das unidades temáticas e o seu processo de aprendizagem por meio de fichas de avaliação e de autoavaliação, disponíveis no ambiente virtual de aprendizagem Moodle. Esse ambiente também serviu como suporte para o desenvolvimento e acompanhamento das diferentes etapas da metodologia de problematização.

O referencial teórico utilizado como fundamento dessa pesquisa foram os estudos de Berbel $(1995,2012,2014)$ e Colombo e Berbel (2007).

Os dados analisados revelaram as diferentes aprendizagens concretizadas pelos alunos participantes do curso, por meio da metodologia aplicada como método de ensino. Um aspecto relevante 
observado foi a vivência das diferentes etapas do Arco de Maguerez na metodologia da problematização pelos alunos, as quais se assemelham às etapas de uma pesquisa científica.

\section{Referencial teórico}

Segundo Berbel (2012), o método originalmente denominado como Arco de Maguerez foi elaborado como um método para alfabetização de adultos que necessitavam adquirir conhecimentos técnicos - teóricos e práticos - nas áreas da mecânica e elétrica. Seu idealizador Charles Maguerez foi um engenheiro francês que, em 1959, deparou-se com o desafio de profissionalizar adultos analfabetos para trabalharem nas regiões do deserto marroquino e do Saara, aprendendo a língua, assimilando a cultura e se apropriando dos conhecimentos específicos dessas áreas. Em 1960, Maguerez desenvolveu o método do Arco, pois entendia que deveria levar em consideração as características do público a ser alfabetizado e os conhecimentos a serem aprendidos, não podendo alfabetizar adultos da mesma forma como as escolas da época alfabetizavam as crianças. Isto é, “[...] nos anos 1960-1970, o método era uma maneira de ensinar as pessoas a adquirirem um conhecimento a ser empregado por elas na prática" (MAGUEREZ, 2012, p. 13, prefácio).

$\mathrm{O}$ arco apresentava cinco etapas que se organizavam numa progressão pedagógica desenvolvida em três momentos: observação, discussão e execução. As etapas foram assim definidas: 1. Observação da realidade (OR) e problema; 2. Observação de uma maquete, simplificando e simbolizando a realidade $(\mathrm{OM}) ; 3$. Discussão sobre esquemas (de conteúdos), permitindo uma generalização (DS); 4. Execução sobre a maquete, permitindo dar imediatamente um valor aos símbolos (EM); 5. Execução na realidade (ER).

Os estudos realizados por Berbel (2012) identificaram que, na década de 1970, Bordenave e Pereira (1982) tornaram público o Arco de Maguerez, por meio do livro Estratégias de ensino-aprendizagem, renomeando a segunda, terceira e quarta etapas, reconhecendo o potencial da proposta metodológica para a formação do- 
cente, por meio da educação problematizadora. A metodologia da problematização com o Arco de Maguerez (BERBEL, 2007 apud BORDENAVE; PEREIRA, 1982) passou assim a apresentar cinco etapas redefinidas: 1. Observação da realidade (problema); 2. Pontos-chave; 3. Teorização; 4. Hipóteses de solução; 5. Aplicação à realidade (prática).

A primeira etapa - Observação da realidade (problema) - não apresenta resposta pronta, já elaborada. Ocorre a partir da seleção de um aspecto da realidade que dará origem ao problema que será estudado. Assim, o problema surge da realidade observada, retirado da realidade concreta constituída por muitas dimensões, tornandose complexo e se relaciona com o tema de estudo.

Os alunos são orientados pelo professor a olhar atentamente e registrar sistematicamente o que perceberem sobre a parcela da realidade em que aquele tema está sendo vivido ou acontecendo, podendo para isso serem dirigidos por questões gerais que ajudem a focalizar e não fugir do tema. (BERBEL, 1995, p. 142).

Na segunda etapa - Pontos-chave - são identificados e selecionados os fatores ou aspectos mais importantes constituintes do problema.

Podem ser expressos de forma variada: questões básicas que se expressam para o estudo; afirmações sobre aspectos do problema; tópicos a serem investigados; ou, ainda, por outras formas. Assim, possibilita-se a criatividade e flexibilidade nessa elaboração, após a compreensão do problema pelo grupo. (COLOMBO; BERBEL, 2007, p. 125).

A terceira etapa - Teorização - se caracteriza pela análise da estrutura e causas do problema para buscar possíveis soluções por meio de estudos, reflexões, discussões e pesquisas em diferentes autores. É a compreensão do problema de forma científica.

É o momento de construir respostas mais elaboradas para o problema.

Os dados obtidos, registrados e tratados, são analisados e discutidos, 
buscando-se um sentido para eles, tendo em vista sempre o problema. (COLOMBO; BERBEL, 2007, p. 125).

A quarta etapa - Hipóteses de solução - é a elaboração fundamentada, a partir dos estudos realizados na etapa anterior, de hipóteses, isto é, o que é possível fazer para resolver o problema. Segundo as autoras, "[...] a criatividade e originalidade devem ser bastante estimuladas para se pensar nas alternativas de solução" (COLOMBO; BERBEL, 2007, p. 125).

$\mathrm{Na}$ quinta etapa - Aplicação à realidade - são elaboradas práticas concretas, planejadas ações para resolver o problema visando transformar a realidade originalmente observada, em algum grau, considerando que essa realidade é ponto de partida e chegada.

Segundo Colombo e Berbel (2007), a metodologia da problematização com o Arco de Maguerez promove a formação docente contextualizada e ampliada e se caracteriza como uma metodologia de ensino que possibilita a construção do conhecimento pelo aluno; provoca o ensino por meio da pesquisa e pode auxiliar nas mudanças da realidade educacional; e entende a educação como prática social emancipadora.

$\mathrm{Na}$ perspectiva das autoras,

A riqueza dessa metodologia está em suas características e etapas, mobilizadoras de diferentes habilidades intelectuais dos sujeitos, demandando, no entanto, disposição e esforços pelos que a desenvolvem no sentido de seguir sistematizadamente a sua orientação básica, para alcançar os resultados educativos pretendidos. (COLOMBO; BERBEL, 2007, p. 124).

A metodologia da problematização com o Arco de Maguerez é utilizada em diferentes cursos de graduação, tais como Ciências Agrárias, Ciências da Saúde, Medicina, Enfermagem, Pedagogia, e outros, e no Programa de Mestrado em Educação da Universidade Estadual de Londrina (UEL), em disciplinas de dissertação.

É utilizada em todo o Brasil, em cursos de graduação e pósgraduação, com resultados positivos na realidade observada, refletindo o seu potencial metodológico e educacional. 
Entendemos que essa metodologia pode ser um método de ensino utilizado como uma alternativa de superação da pedagogia da transmissão, do ensino tradicional baseado em aula expositiva, centrado no professor, que não considera a aprendizagem do aluno, como já exposto em diversos estudos, como, por exemplo, em pesquisa realizada por Berbel (1995).

Nos estudos de Bordenave e Pereira (1982), foi possível identificarmos dois tipos de educação, a bancária ou convergente e a problematizadora ou libertadora. Nessa última, o aluno tem participação ativa e diálogo constante com o professor.

Essa metodologia surge dentro de uma visão de educação libertadora, voltada para a transformação social. Tem como ponto de partida a realidade onde as questões em estudo estão acontecendo. A metodologia da problematização pretende retornar à realidade, com informação, sugestão e, às vezes, ações efetivas. Mobiliza o potencial social, político e ético dos profissionais em formação.

A relação teoria e prática é permanente e o movimento é de ação-reflexão-ação. O feedback é constante, para que o aluno pense no caminho percorrido e a avaliação é formativa.

\section{Procedimentos metodológicos}

A pesquisa com o uso da metodologia da problematização foi realizada em duas unidades temáticas componentes da matriz curricular do curso de Pedagogia da PUC-SP.

Inicialmente, houve a necessidade de definirmos um perfil de cada turma participante a partir de algumas características, tais como: trajetória profissional inicial dos(as) alunos(as); o período a ser cursado e o plano de ensino das unidades temáticas. Além disso, para que fosse possível a vivência da metodologia da problematização, trabalhamos em parceira com mais duas unidades temáticas: Estágio Supervisionado nos Anos Iniciais ( $6^{\circ}$ período) e Estágio Supervisionado nas Diferentes Modalidades de Gestão ( $8^{\circ}$ período).

$\mathrm{Na}$ turma MA8 ( $8^{\circ}$ período, matutina), na unidade temática Escola: diferentes espaços e serviços de apoio pedagógico, foi 
possível desenvolver a metodologia da problematização com as dezessete alunas participantes, distribuídas em seis grupos formados a partir da mesma unidade escolar para a realização do estágio supervisionado em gestão escolar.

Já nas turmas MA6 ( $6^{\circ}$ período, matutina, vinte alunas participantes) e NA6 ( $6^{\circ}$ período, noturna, dezessete alunos(as) participantes), na unidade temática Metodologias Específicas: natureza, ciências, meio ambiente, saúde, além do critério da unidade escolar para a realização do estágio supervisionado nos anos iniciais, também levou-se em consideração o local de trabalho dos(as) alunos(as), o que resultou no desenvolvimento da metodologia da problematização de forma individual.

Em concordância com os(as) alunos(as), o horário das aulas das duas unidades temáticas foi adaptado, de duas horas-aula semanais para quatro horas-aula quinzenais, com a intenção de ampliar o tempo de encontro para discussões em sala (uma manhã e uma noite) com os grupos e individualmente com os alunos, bem como as orientações necessárias e o acompanhamento sistemático para a aplicação da metodologia da problematização e a vivência das etapas do Arco de Marguerez. Como um dos recursos pedagógicos para que a orientação, a correção e o acompanhamento dos trabalhos ocorressem, foi utilizado o AVA Moodle o que possibilitou a comunicação permanente entre professora e alunas.

É importante ressaltar que a apresentação, discussão e o aceite da proposta de trabalho, individual e em grupo, a adequação do horário das aulas, do trabalho em parceria com outras unidades temáticas, e o uso do ambiente virtual de aprendizagem Moodle resultaram na participação, no desempenho e desenvolvimento da responsabilidade e autonomia, além do estabelecimento de estudo e trabalho contínuos. No sentido de avaliar o uso da metodologia da problematização como um método de ensino, foram construídas duas fichas avaliativas. Ao final do semestre letivo, os alunos envolvidos avaliaram o desenvolvimento das unidades temáticas e o seu processo de aprendizagem por meio dessas fichas de avaliação e de 
autoavaliação. Essas foram postadas no ambiente virtual de aprendizagem Moodle para facilitar o acesso dos alunos participantes. As respostas obtidas a partir destes instrumentos de coleta de informações foram alvo de análise e interpretação da experiência didática.

A experiência didática contou com a participação total de cinquenta e oito alunos, distribuídos em três turmas. Para que a orientação e o acompanhamento dos trabalhos ocorressem, foi utilizado o ambiente virtual Moodle, o qual serviu como suporte para a elaboração e desenvolvimento das diferentes etapas da metodologia de problematização.

\section{Análise e discussão dos dados}

Analisamos as respostas fornecidas nas fichas de avaliação das unidades temáticas envolvidas.

Inicialmente, ficou caracterizada, pelas respostas, a importância do estudo e da discussão dos textos que apresentaram a metodologia da problematização com o Arco de Maguerez como metodologia de ensino a ser vivenciada pelas turmas. Os textos estudados permitiram a compreensão dessa metodologia a partir da fundamentação teórica apresentada pelo diálogo com diversos autores, como, por exemplo, Araújo e Sastre (2009), Berbel (2012) e Colombo e Berbel (2007), e das concepções pedagógicas que a sustentam, bem como a compreensão das cinco etapas de realização e suas finalidades.

As respostas obtidas indicaram que o desenvolvimento dessa metodologia como método de ensino contribuiu para a formação profissional crítica e reflexiva, promoveu a construção do processo de aprender, individualmente e em grupo. No decorrer do semestre, por meio da elaboração das etapas, os alunos efetivaram a aprendizagem ativa durante a qual se debruça e observa uma parcela da realidade; identifica problemas e seleciona um relevante; discute o problema em seus diversos aspectos na busca de fundamentação teórica, por meio do estudo de diferentes autores, possibilitando construção do conhecimento para sugerir hipóteses de soluções e prepara uma ação transformadora para intervir na realidade. 
A resposta de uma das alunas revela que

[...] a vivência da metodologia foi enriquecedora como estratégia de ensino e aprendizagem, permitiu pensar em um problema relevante e buscar caminhos definindo como poderíamos agir, revisitamos aprendizagens já construídas, houve diálogo e discussão, saímos da concepção tradicional de educação. (A1)

Para outra aluna, o desenvolvimento dessa metodologia como método de ensino

[...] possibilitou o processo de ação-reflexão-ação que estimulou o pensar, repensar e reconstruir o que não concordamos no nosso cotidiano escolar, tendo oportunidade de propor uma intervenção consciente, ou seja, a prática reflexiva preparando para uma ação transformadora nos contextos profissionais. (A2)

Foi evidenciado, também, por outra aluna que

[...] a relação teoria e prática por meio da vivência das etapas, o aprender a pesquisar e planejar ajudou a pensar - desde a observação do cotidiano até a reconstrução do conhecimento científico e aplicação desse na realidade a ser transformada, o amadurecimento de alguns realizou mudanças significativas em nossas atitudes, deixamos de lado o fazer simplesmente por fazer! (A3)

Outra resposta confirma a contribuição para esse amadurecimento:

[...] o método de ensino desenvolvido - Metodologia da Problematização com o Arco de Maguerez - se apresentou de forma muito eficaz e relevante para o ensino superior e a aprendizagem de adultos, foi outra forma de construção do processo de ensino aprendizagem, muito mais atraente, motivadora e significativa para o aluno, do que a abordagem tradicional de ensino. (A7)

Os alunos consideraram que foi uma proposta muito interessante, partindo da experiência que já tinham como estagiários e/ 
ou auxiliares de sala; puderam elaborar propostas de soluções para os problemas, embasadas nas teorias de autores que defendem uma educação significativa e investigativa.

Confirmamos que foi possível desenvolver no futuro docente o potencial intelectual, a capacidade de análise, de julgamento, avaliação crítica e a promoção da aprendizagem, pois houve mais estudo dos textos relacionados às unidades temáticas e aos problemas selecionados, uma vez que havia a necessidade de elaboração da etapa três, teorização para seguir as demais etapas:

[...] leitura séria dos textos... É uma metodologia de ensino que possibilita ao professor e ao aluno trabalharem de forma mais dinâmica. (A4)

Durante o semestre, na elaboração das etapas do Arco de Maguerez, algumas dificuldades foram sentidas, tais como: a identificação e elaboração do problema a partir da observação da realidade, etapa um; a elaboração da teorização, etapa três, na unidade temática Metodologias Específicas: natureza, ciências, meio ambiente, saúde, sendo necessárias novas explicações realizadas pela docente, e outras indicações de textos que trouxeram pistas para a solução do problema selecionado.

Os alunos consideraram o método de ensino como uma estratégia de aprendizado diferenciada, que contribuiu para a compreensão de como trabalhar Ciências Naturais por meio da sequência de ensino investigativa (SEI), na educação infantil e no ensino fundamental I:

A proposta foi excelente para o ensino e aprendizagem da unidade temática Metodologias específicas: natureza/ciências/meio ambiente/saúde. (A10)

Houve, por parte de alguns alunos, recomendações para utilizar mais vezes essa metodologia de ensino, pois:

[...] nos aproximou da realidade, unindo teoria e prática e a compreensão dos passos para elaboração de uma proposta de intervenção. (A6) 
Na unidade temática Escola: diferentes espaços e serviços de apoio pedagógico, os alunos relacionaram a concepção de educação projetos de trabalho, elaborada por Hernández e Ventura (1998), e a metodologia da problematização com o Arco de Maguerez proposta como método de ensino. Ambos os autores trabalham a ação educativa a partir da pesquisa.

Críticas também foram identificadas nas respostas dos alunos da turma do noturno, na qual não houve adequação do horário das aulas: pouco tempo para realização do trabalho; falta de troca de experiências entre eles; os alunos deveriam apresentar as diversas realidades observadas na etapa um e, sucessivamente, as demais etapas, para conhecimento do grupo; alguns textos selecionados foram considerados difíceis, gerando dificuldades de compreensão.

$\mathrm{Na}$ continuidade do estudo, analisamos as respostas fornecidas pelas fichas de autoavaliação, nas mesmas unidades temáticas, com destaque nas questões: Quais foram os principais conceitos aprendidos? $\mathrm{O}$ que foi possível desenvolver em minha atuação como estagiário?

Em Metodologias Específicas: natureza, ciências, meio ambiente, saúde, os principais conceitos aprendidos foram:

[...] a sequência de ensino investigativa (SEI) como estratégia metodológica para Ciências Naturais na Educação Infantil e no Ensino Fundamental I apresenta etapas similares à Metodologia da Problematização com o Arco de Maguerez vivenciada. (A9)

Isto é, aprender e ensinar a partir de problemas observados na realidade, encontrar seus elementos constituintes, elaborar e testar hipóteses, pesquisar respostas nas teorias e propor soluções, ações de intervenção. A compreensão dos conceitos estruturantes da área, dos princípios, bem como dos critérios estruturantes - o conteúdo, a metodologia e o papel do professor - foram aprendidos a partir da identificação dos problemas relacionados ao ensino de Ciências Naturais observado nas escolas: 
[...] tornaram as leituras prévias dos textos e as discussões realizadas em aula mais significativas. (A13)

$\mathrm{Na}$ unidade temática Escola: diferentes espaços e serviços de apoio pedagógico, os principais conceitos aprendidos foram os relacionados a:

[...] formação continuada dos docentes; a importância do trabalho da equipe escolar; a gestão democrática da escola; a elaboração de projetos, como se dá a relação teoria e prática no cotidiano escolar, e a compreensão da integração permanente entre teoria e a prática. (A3)

Esses conceitos foram aprendidos por meio da leitura de textos estudados nas unidades temáticas já cursadas em semestres anteriores.

$\mathrm{Na}$ atuação como estagiários nas diferentes unidades escolares, os participantes deste estudo perceberam que foi importante problematizar a realidade, fundamentar a análise com estudos de textos promovendo atuações mais críticas, com base pedagógica.

\section{Considerações finais}

As metodologias ativas vieram para atender aos novos perfis profissionais que vêm surgindo com o passar do tempo, e elas estão em um processo de constante aperfeiçoamento. Para Freire (1996 apud BERBEL, 2012), as metodologias ativas são formas de aprendizagens baseadas na resolução de problemas, construindo conhecimentos a partir de conhecimentos já consolidados e experiências prévias dos sujeitos. Bastos (2006 apud BERBEL, 2012) relata a importância do professor como um facilitador da aprendizagem, e da importância da análise individual e coletiva para a resolução do problema, após observação. Mitri (2008 apud BERBEL, 2012) concorda com os autores anteriores na questão de que os alunos, a partir de uma problematização, examinam, refletem, relacionam com o que já sabem e ressignificam suas descobertas. É uma me- 
todologia que acredita na educação como uma prática social e não apenas individual.

O estudo realizado indicou a possibilidade de desenvolver o processo de ensino e aprendizagem a partir da pesquisa no ensino superior. Incentivou o ensino participativo e a aprendizagem significativa, por meio do acompanhamento contínuo do professor, da necessária adequação dos horários de aulas, do empenho, do estudo e da responsabilidade dos alunos.

Pode-se concluir que os professores de diferentes áreas podem conduzir a formação dos alunos, por meio dessa metodologia ativa, uma vez que desperta a curiosidade nos discentes para que se interessem pelos problemas identificados. $\mathrm{Na}$ medida em que isto ocorre, o professor promove a autonomia do aluno e o encoraja à busca de soluções e novas descobertas. Estimula os alunos a observarem, pois é mediante a observação da realidade que o aluno vai selecionar o problema a estudar. Como mediador, pode conduzir os alunos a problematizarem aspectos da realidade concreta, relacionando-os com temas de estudo, além de proporcionar a vivência metodológica que se assemelha aos passos de uma pesquisa científica.

A pesquisa ratifica os dados conclusivos dos estudos de Berbel (2012), no sentido de que os professores do ensino superior de diferentes áreas da graduação vinculadas à formação docente podem promover a vivência da metodologia da problematização como método de ensino.

\section{Referências}

ARAÚJO, U. F.; SASTRE, G. (Org.). Aprendizagem baseada em problemas no ensino superior. São Paulo: Summus, 2009.

BERBEL, N. A. N. Metodologia da problematização: uma alterativa metodológica apropriada para o ensino superior. Semina: Ciências Sociais e Humanas, Londrina, v. 16, n. 2, Ed. Especial, p. 9-19, out. 1995.

A metodologia da problematização com o Arco de Maguerez: uma reflexão teórico-epistemológica. Londrina: EDUEL, 2012. 
A problematização e a aprendizagem baseada em problemas: diferentes termos ou diferentes caminhos? Disponível em: <http://www.scielo.br/ pdf/icse/v2n2/08>. Acesso em: 4 jul. 2014.

BORDENAVE, J. D.; PEREIRA, A. M. Estratégias de Ensino Aprendizagem. 28. ed. Petrópolis: Vozes, 1982.

COLOMBO, A. A.; BERBEL, N. A. N. A Metodologia da Problematização com o Arco de Maguerez e sua relação com os saberes de professores. Semina: Ciências Sociais e Humanas, Londrina, v. 28, n. 2, p. 121-146, jul./dez. 2007.

HERNÁNDEZ, F; VENTURA, M. A organização do currículo por projetos de trabalho. Tradução de Jussara H. Rodrigues. 5. ed. Porto Alegre: Artes Médicas, 1998.

Submetido em: 16-3-2018

Aceito em: 21-3-2018 